\section{In Vivo Shoot Regeneration Promoted by Shading the Cut Surface of the Stem in Tomato Plants}

\author{
Masafumi Johkan, Genjirou Mori, Kazuhiko Mitsukuri, \\ Keiichirou Mishiba, Toshinobu Morikawa, and Masayuki Oda ${ }^{1}$ \\ Graduate School of Life and Environmental Sciences, Osaka Prefecture \\ University, Gakuentyou1-1, Sakai, Nakaku 5998531, Japan
}

Additional index words. adventitious bud, in vivo, Lycopersicon esculentum, phenolic compounds, shading, vegetative propagation

\begin{abstract}
The aim of this study was to establish an alternative method to produce clones of tomato plants by modification of the complete decapitation method, which regenerates multiple shoots from the cut surfaces of the main and lateral stems of plants grown in vivo. Shading the stems of tomato plants drastically increased the number of regenerated shoots from 2.4 in controls with unshaded stems to 36.2 in shaded stems. In shaded stems, the concentrations of chlorophyll and phenolic compounds were stable for 3 weeks after cutting, whereas these amounts increased in unshaded stems. Inhibiting the production of phenolic compounds in the shaded stem tissues was associated with an acceleration of shoot formation in vivo.
\end{abstract}

Tomato plants (Lycopersicon esculentum Mill.) are commonly propagated by seed. Recently, however, several tomato cultivars reproduced by vegetative propagation have been released for tomato production. Such cultivars developed through mutagenesis can be rapidly released because they do not require a process of genetic fixation. However, their propagation efficiency is lower than that of seed propagation, and therefore their distribution has been limited. Although in vitro propagation is effective for multiplication of clones, it is expensive and often generates somatic mutations (Padmanabhan et al., 1974).

The complete decapitation method (CDM), which regenerates multiple shoots from the cut surfaces of the main and lateral stems of plants grown in vivo, was reported as a new vegetative propagation method in tomato plants (Harada et al., 2005). The authors reported that 79 shoots regenerated from calluses on the stock plant $36 \mathrm{~d}$ after decapitation. Propagation efficiency using the CDM was higher than that of lateral shoot propagation but lower than that of seed propagation. Therefore, CDM has potential to be used as a practical method for formation of multiple shoots.

Injury to plants causes oxidative stress, which alters many metabolic processes and reduces growth (Foyer et al., 2002; Prasad et al., 1994). One of the main defense mechanisms induced under oxidative stress is phenolic metabolism (Bharti and Khurana, 1997), which is one of the important resistance responses to various types of stress. Wounding of plant tissues increases the activity of phenylalanine ammonia lyase and causes plant cells to biosynthesize phe-

Received for publication 26 July 2007. Accepted for publication 21 Sept. 2007.

${ }^{1}$ To whom reprint requests should be addressed; e-mailmoda@plant.osakafu-u.ac.jp buds (solid line) in decapitated tomato plants.
Phenolic compounds are secondary metabolites in plant tissue and their biosynthesis is greatly influenced by light (Crippen and Morrison, 1986). For instance, field shading of mango decreased the concentration of phenolic compounds in the tissue and promoted morphogenesis in vitro (Sharma and Singh, 2002). We therefore hypothesized that a decrease in phenolic compounds would improve shoot generation efficiency using CDM. In this study, we examine if shading of stems' cut surfaces promotes the formation of callus, adventitious buds, and shoots in tomato plants grown in vivo.

\section{Materials and Methods}

Plant materials. Germinated seeds of tomato plants (L. esculentum cv. Momotaro) were sown in a 72 -cell tray $(50 \mathrm{~mL} /$ cell $)$ filled with a $2: 1(\mathrm{v} / \mathrm{v})$ mixture of peatmoss and vermiculite. The seedlings were grown in a greenhouse with a light transmissivity of $55 \%$ and supplied with a nutrient solution containing 4.6 nitrogen, 1.3 phosphorus, 2.2 potassium, 1.1 calcium, 0.4 magnesium, in $\mathrm{mol} \cdot \mathrm{L}^{-1}$. When the sixth true leaf had unfolded, the main stems were cut between the second and third true leaves with a sharp razor blade. Cut surfaces of the stems were covered with or without an aluminum cap immediately after cutting of the stem. After decapitation of the main shoot, all lateral shoots were excised at the base. The aluminum cap remained on the cut surface of the stem until formation of adventitious buds started.

Promotion of shoot regeneration. Tomato seeds were sown on 21 Mar. 2006 and stems were cut on 15 May. Shoots regenerated from callus on the cut surface of stems were harvested when the regenerated shoots were $5 \mathrm{~cm}$ long. Each experiment consisted of 12 replicates.

Quantification of chlorophyll. Tomato seedlings were sown on 15 Mar. 2007 and

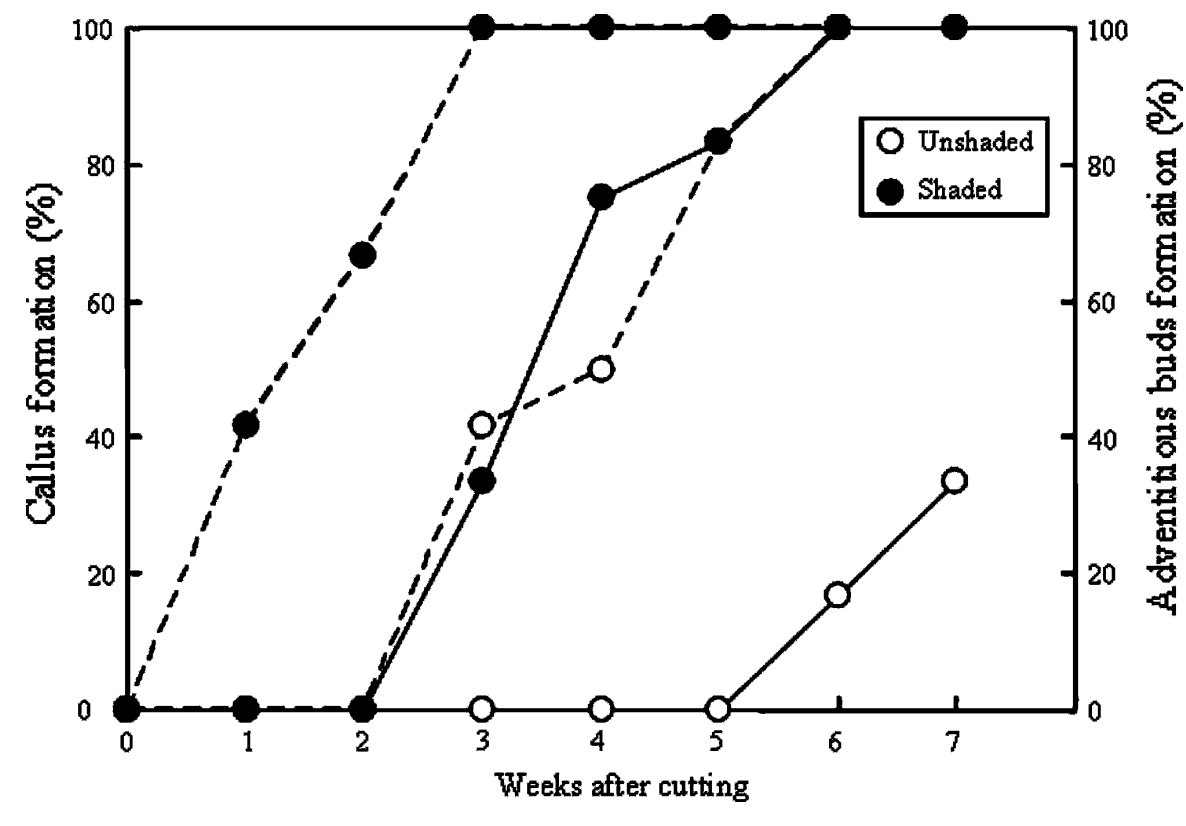

Fig. 1. Effects of shading the cut surface of stems on formation of callus (broken line) and adventitious 
stems were cut on 9 May. Cut surfaces of stems of shaded and nonshaded plants were sampled $2 \mathrm{~cm}$ below the top of the cut surface at 3 weeks after cutting (WAC). Chlorophyll was extracted from $0.2 \mathrm{~g}$ fresh weight with $4 \mathrm{~mL} \mathrm{~N}, N$-dimethylformamide at $4{ }^{\circ} \mathrm{C}$ for $5 \mathrm{~d}$ and determined according to Inskeep and Bloom (1985).

Quantification of phenols. Tomato seedlings were sown on 11 Oct. 2006 and stems were cut on $20 \mathrm{Dec}$. Cut surfaces of stems of shaded and nonshaded plants were sampled $2 \mathrm{~cm}$ below the cut surface at 3 WAC. Phenols were extracted with $80 \%$ methanol. The concentration of phenols was determined as described by Singleton and Rossi (1965).

\section{Results}

Promotion of shoot regeneration. In unshaded control stems, callus formation began at 3 WAC and reached $100 \%$ at 6 WAC (Fig. 1). In the shaded plants, callus formation started from $1 \mathrm{WAC}$ and reached $100 \%$ at 3 WAC. Adventitious bud formation was observed from $6 \mathrm{WAC}$ and reached only $33 \%$ at $7 \mathrm{WAC}$ in control stems. In shaded stems, formation of adventitious buds was observed from $3 \mathrm{WAC}$ and reached $100 \%$ at 6 WAC. Therefore, shading the cut surface of stems promoted formation of callus and adventitious buds in tomato plants.

No adventitious buds formed on the cut surface of stems in the unshaded controls (Fig. 2A), whereas many adventitious buds formed in the shaded stems at 3 WAC (Fig. 2B). Subsequently, only a few adventitious buds formed in unshaded control stems (Fig. 2C), whereas in shaded stems, many shoots attained a length of $5 \mathrm{~cm}$ at $6 \mathrm{WAC}$ (Fig. 2D). Adventitious buds began to form in shaded stems at 3 WAC and in unshaded stems at 6 WAC. The density of adventitious buds in shaded stems was markedly higher than that in nonshaded stems (Fig. 2B-C).

Shading significantly increased the number of total regenerated shoots per tomato plant (Fig. 3). The average number of harvested shoots markedly increased from an average of 2.4 per stem in unshaded controls to 36.2 per stem in shaded stems at $10 \mathrm{WAC}$.

Effects of shading on concentrations of chlorophyll and phenols. The shaded stem was light green, whereas control stems were dark green. The chlorophyll concentration and the ratio of chlorophyll $a$ to $b$ of shaded stems at $3 \mathrm{WAC}$ was not significantly different from that in 0 WAC plants and significantly lower than in 3 WAC control stems (Table 1).

Shaded stems showed decreased concentrations of phenolic compounds at $3 \mathrm{WAC}$ (Table 2). The concentrations of phenols in shaded stems at $3 \mathrm{WAC}$ were the same as those in $0 \mathrm{WAC}$ plants and were significantly lower than in control stems at 3 WAC.

\section{Discussion}

Shoot formation by CDM, which regenerates multiple shoots from the callus formed on the cut surfaces of the main and lateral
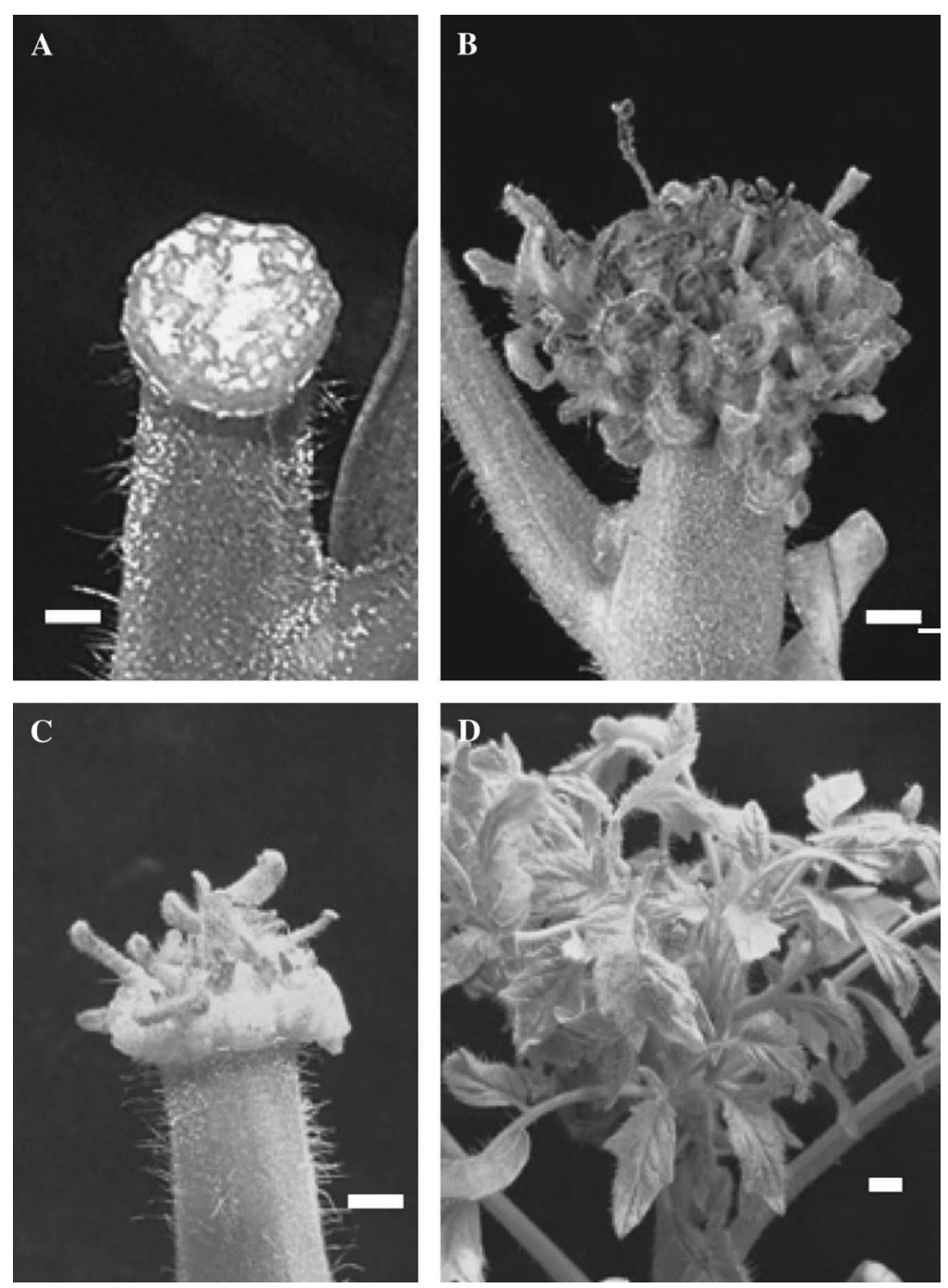

Fig. 2. Regeneration of adventitious buds from the cut surface of stems at 3 (A and B) or $6(\mathbf{C}$ and $\mathbf{D})$ weeks after stem cutting in tomato. Unshaded: $\mathbf{A}$ and $\mathbf{C}$, shaded: $\mathbf{B}$ and $\mathbf{D}$. Bars $=10 \mathrm{~mm}$.

stems (Harada et al., 2005), depends on the same principle as shoot formation in in vitro tissue culture. Because this method requires only cutting the main and lateral stems in the field, the CDM is easier and less expensive than in vitro methods. However, the efficiency of propagation in CDM is lower than that in vitro. In our study, shading the cut surfaces of the stems increased the shoot formation using the CDM to 15 times that of unshaded controls. Therefore, shading stems' cut surfaces is advantageous to reproduce vegetative clones using the CDM.

Oxidative stress occurs at the cut surfaces of stems in the CDM. Stress conditions trigger oxidative metabolism in plants, and active oxygen species are highly reactive and damage proteins, chlorophylls, membrane lipids, and nucleic acids (Borochov and Woodson, 1989; Sohal et al., 2002). To prevent or alleviate this damage, plants have developed various mechanisms based on antioxidants (Hodges et al., 1997; Jahnke et al., 1991). Polyphenols possess ideal structural chemistry for free radical scavenging activity (Blokhina et al., 2003). When plants suffer abiotic or biotic damage, the tissue

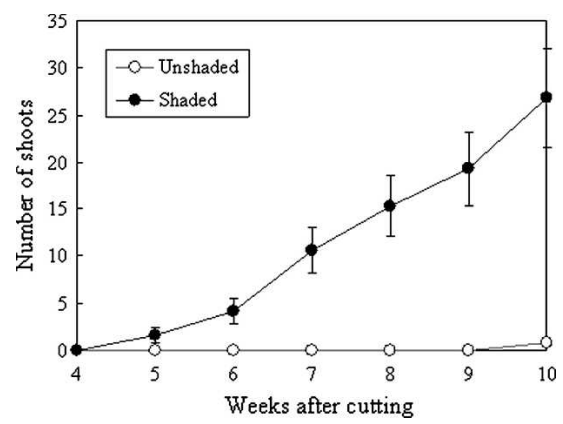

Fig. 3. Effects of shading the cut surface of stems on the number of shoots harvested in decapitated tomato plant. Bars represent SES $(n=12)$.

around the wounded site accumulates phenolics (Hudgins and Franceschi, 2004). In our study, the concentration of phenolic compounds in shaded stems was lower than that in unshaded control stems. We suggest that protecting cut surfaces from the light reduced oxidative stress in the shaded stems.

Tissue browning is associated with the suppression of regeneration in callus culture and frequently occurs in vitro (Pirttila et al., 
Table 1. Effects of shading on concentrations of chlorophyll and the ratio of chlorophyll $a$ to $b$ in the cut end of the stems of tomato plants.

\begin{tabular}{lcc}
\hline Treatment & $\begin{array}{c}\text { Chlorophyll } \\
\left(\mathrm{mg} \cdot \mathrm{g}^{-1} \mathrm{FW}\right)\end{array}$ & $\begin{array}{c}\text { Chlorophyll } \\
\mathrm{a} / \mathrm{b} \text { ratio }\end{array}$ \\
\hline On the day of cutting & $4.53 \mathrm{a}^{\mathrm{z}}$ & $1.47 \mathrm{a}$ \\
3 weeks after cutting & & \\
$\quad$ Unshaded & $7.52 \mathrm{~b}$ & $1.38 \mathrm{~b}$ \\
Shaded & $4.08 \mathrm{a}$ & $1.44 \mathrm{a}$ \\
\hline
\end{tabular}

${ }^{\mathrm{z}}$ Average values followed by the same letter are not significantly different at $P<0.05$ (Tukey's multiple range test).

$\mathrm{FW}=$ fresh weight.

Table 2. Effects of shading on concentrations of total phenolic compounds in the cut end of the stems of tomato plants.

\begin{tabular}{lcc}
\hline & \multicolumn{2}{c}{ Concn of phenols $\left(\mathrm{mg} \cdot \mathrm{g}^{-1} \mathrm{FW}\right)$} \\
\cline { 2 - 3 } Treatment & $0 \mathrm{WAC}^{\mathrm{z}}$ & $3 \mathrm{WAC}$ \\
\hline Unshaded & $15 \mathrm{a}^{\mathrm{y}}$ & $27 \mathrm{~b}$ \\
Shaded & - & $14 \mathrm{a}$ \\
\hline
\end{tabular}

${ }^{\mathrm{z}}$ Weeks after cutting.

${ }^{y}$ Average values followed by the same letter are not significantly different at $P<0.05$ (Tukey's multiple range test).

$\mathrm{FW}=$ fresh weight.

2004; Sharma and Singh, 2002; Tang and Newton, 2004a). This phenomenon results from oxidation of precursor phenolic compounds by PPO (Saltveit et al., 2005). Therefore, interfering with the synthesis or oxidation of phenolic compound precursors plays an important role in shoot regeneration by CDM. The cut surface of the shaded stems had lower concentrations of total phenolic compounds and concomitantly regenerated more and longer (greater than $5 \mathrm{~cm}$ ) shoots than control stems. Indeed, previous studies also observed that low concentrations of phenolic compounds in plant tissues promoted shoot regeneration in vitro (Marks and Simpson, 1990; Raghuvanshi and Srivastava, 1995; Sharma and Singh, 2002). We suggest that the increased shoot formation with CDM in shaded stems is the result of lower concentration of phenolic compounds.

The concentration of phenolic compounds was lower in the shaded stems than unshaded stems. Phenolic compounds are secondary metabolites and are associated with age. For instance, differentiation generally occurs more readily in juvenile tissue than in mature tissue in vitro (De Donato et al., 1989), and tissue browning is frequently observed in callus cultures derived from mature explants in some of the higher plant species (Tang et al., 2004b). The chlorophyll concentration was also lower in shaded stems than unshaded stems. Chlorophyll concentration increases and the ratio of chlorophyll $a$ to $b$ become greater as leaves mature (James et al., 1999). Shading the cut surface of the stem might retain tissue at the juvenile stage at the cut surface, in which callus formation and adventitious bud formation were accelerated after CDM treatment.

Low concentrations of phenolic compounds in etiolated shoots are often caused by blocking of light (Crippen and Morrison, 1986; Marks and Simpson, 1990; Sharma and Singh, 2002). Ultraviolet damages living organisms (Landry et al., 1995), and the exposure to ultraviolet can be a comparatively mild stimulus in the synthesis of phytophenolic compounds (Shetty et al., 2002). Therefore, blocking ultraviolet light may be one way in which shading the cut stems with foil promotes shoot regeneration after CDM.

In conclusion, shading the cut surface of tomato stems accelerates the formation of callus and adventitious buds and increases the number of shoots regenerated. This may be caused by the low concentration of the phenolic compounds in the shaded tissue. In the future, CDM could be used as a rapid method to produce transgenic plants. Because high efficiency of in vitro regeneration is required for the production of transgenic plants (Tang and Newton, 2003; Zheng et al., 2005), CDM with shading treatment might be used in the production of transgenic tomato plants.

\section{Literature Cited}

Bharti, A.K. and J.P. Khurana. 1997. Mutants of Arabidopsis as tools to understand the regulation of phenylpropanoid pathway and UVB protection mechanisms. Photochem. Photobio. 65:765-776.

Blokhina, O., E. Virolainen, and K.V. Fagerstedt. 2003. Antioxidants, oxidative damage and oxygen deprivation stress: A review. Ann. Bot. (Lond.) 91:179-194.

Borochov, A. and W.R. Woodson. 1989. Physiology and biochemistry of flower petal senescence. Hort. Rev. (Amer. Soc. Hort. Sci.) 11:15-43.

Crippen, D.D. and J.C. Morrison. 1986. The effect of sun exposure on the phenolic content of Cabernet Sauvignon berries during development. A. J. Enol. Viticult. 37:243-247.

De Donato, M., E. Perucco, P. Chiavazza, and E. Panei. 1989. Activation of nuclear DNA replication and mitosis in excised cotyledons of Capsicum annuum. Plant Sci. 63:217-225.

Foyer, C.H., H. Vanacker, L.D. Gomez, and J. Harbinson. 2002. Regulation of photosynthesis and antioxidant metabolism in maize leaves at optimal and chilling temperature: Review. Plant Physiol. Biochem. 40:659-668.

Gill, M.I., J.R. Gorny, and A.A. Kader. 1998. Responses of 'Fuji' apple slices to ascorbic acid treatments and low-oxygen atmospheres. HortScience 33:305-309.

Harada, M., M. Oda, G. Mori, and H. Ikeda. 2005. Mass regeneration of shoots from cut surface of stems in tomato stock plants. J. Jpn. Soc. Hort. Sci. 74:479-481.

Hodges, D.M., C.J. Andrews, D.A. Johnson, and R.I. Hamilton. 1997. Antioxidant enzyme and compound responses to chilling stress and their combining abilities in differentially sensitive maize hybrids. Crop Sci. 37:857-863.

Hudgins, J.W. and V.R. Franceschi. 2004. Methyl jasmonate-induced ethylene production is responsible for conifer phloem defense responses and reprogramming of stem cambial zone for traumatic resin duct formation. Plant Physiol. 135:2134-2149.

Inskeep, W.P. and P.R. Bloom. 1985. Extinction coefficients of chlorophyll $a$ and $b$ in $N, N$ dimethylfolmamide and $80 \%$ acetone. Plant Physiol. 77:483-485.

Jahnke, L.S., M.R. Hull, and S.P. Long. 1991. Chilling stress and oxygen metabolizing enzymes in Zea mays and Zea diploperennis. Plant Cell Environ. 14:97-104.

James, S.A., W.K. Smith, and T.C. Vogelmann. 1999. Ontogenetic differences in mesophyll structure and chlorophyll distribution in Eucalyptus globulus ssp. globulus (Myrtaceae). A. J. Bot. 86:198-207.

Landry, L.G., C.C.S. Chapple, and R.L. Last. 1995. Arabidopsis mutants lacking phenolic sunscreens exhibit enhanced ultraviolet-B and oxidative damage. Plant Physiol. 109:1159-1166.

Madhusudhanan, K. and B.A. Rahiman. 2000. The effect of activated charcoal supplemented media to browning of in vitro cultures of Piper species. Biol. Plant. 43:297-299.

Marks, T.R. and S.E. Simpson. 1990. Reduced phenolic oxidation at culture initiation in vitro following exposure of field grown stock plants to darkness or low levels of irradiance. J. Hort. Sci. 64:421-428.

Padmanabhan, V., E.P. Paddock, and W.R. Sharp. 1974. Plant formation from Lycopersicon esculentum leaf callus. C. J. Bot. 52:1429-1432.

Pirttila, A.M., P. Joensuu, H. Pospiech, J. Jalonen, and A. Hohtola. 2004. Bud endophytes of Scots pine produce adenine derivatives and other compounds that affect morphology and mitigate browning of callus cultures. Physiol. Plant. 121:305-312.

Prasad, T.K., M.D. Anderson, B.A. Martin, and C.R. Steward. 1994. Evidence for chilling induced oxidative stress in maize seedlings and regulatory role for hydrogen peroxide. Plant Cell 6:65-74.

Raghuvanshi, S.S. and A. Srivastava. 1995. Plant regeneration of Mangifera indica using liquid shake culture to reduce phenolic exudation. Plant Cell Tiss. Org. Cul. 41:83-85.

Saltveit, M.E., Y.J. Choi, and F.A. Tomas-Barberan 2005. Mono-carboxylic acids and their salts inhibit wound-induced phenolic accumulation in excised lettuce (Lactuca sativa) leaf tissue. Physiol. Plant. 125:454-463.

Sharma, R.R. and S.K. Singh. 2002. Etiolation reduces phenolic content and polyphenol oxidase activity at the pre-culture stage and in-vitro exudation of phenols from mango explants. Trop. Agr. 79:94-99.

Shetty, P., M.T. Atallah, and K. Shetty. 2002. Effects of UV treatment on the proline-linked pentose phosphate pathway for phenolics and L-DOPA synthesis in dark germinated Vicia faba. Pro. Biochem. 37:1285-1295.

Singleton, V.L. and J.A. Rossi. 1965. Colorimetry of total phenolics with phosphomolybedicphosphototungstic acid reagents. Amer. J. Enol. Viticult. 16:144-158.

Sohal, R.S., R.J. Mockett, and W.C. Orr. 2002. Mechanisms of aging: An appraisal of the oxidative stress hypothesis. Free Radi. Biol. Medic. 33:575-586.

Stratil, P., B. Klejdus, and V. Kuban. 2007. Determination of phenolic compounds and their antioxidant activity in fruits and cereals. Talanta 71:1741-1751.

Tang, W. and R.J. Newton. 2003. Genetic transformation of conifers and its application in forest biotechnology. Plant Cell Rep. 22:1-15.

Tang, W. and R.J. Newton. 2004a. Increase of polyphenol oxidase and decrease of polyamines correlate with tissue browning in Virginia pine (Pinus virgiana Mill.). Plant Sci. 167:621-628.

Tang, W., R.J. Newton, and V. Outhavong. 2004b. Exogenously added polyamines recover browning tissues into normal callus cultures and improve plant regeneration in pine. Physiol. Plant. 122:386-395.

Zheng, Q., B. Ju, L. Liang, and X. Xiao. 2005. Effect of antioxidants on the plant regeneration and GUS expressive frequency of peanut (Arachis hypogaea) explants by Agrobacterium tumefaciens. Plant Cell Tiss. Org. Cul. 81:83-90. 